\title{
PRODUÇÃO DE HIDROGÊNIO E ETANOL A PARTIR DA FERMENTAÇÃO DA MANIPUEIRA
}

\author{
N.C.S. AMORIM ${ }^{1}$, J. S. MARTINS ${ }^{2}$ e E. L. C. AMORIM ${ }^{2}$ \\ ${ }^{1}$ Instituto Federal de Alagoas \\ ${ }^{2}$ Universidade Federal de Alagoas, Centro de Tecnologia \\ E-mail para contato: eduardo.lucena@uol.com.br
}

\begin{abstract}
RESUMO - Este trabalho teve como objetivo avaliar a produção de hidrogênio e etanol a partir da manipueira em reator anaeróbio de leito fluidizado. $\mathrm{O}$ reator foi operado em 5 fases em função do tempo de detenção hidráulica $(\mathrm{TDH})(8,6,4,2$ e 1 h). O reator foi inoculado com lodo proveniente de uma lagoa anaeróbio que tratava resíduos de suinocultura. Foram observadas a presença dos ácidos acético, butírico e propiônico, além do etanol. $\mathrm{O}$ etanol foi o metabólito mais presente durante toda a operação do reator (variando de 1,87-100\%). O rendimento de hidrogênio (HY) variou de 0,31-1,91 mol $\mathrm{H}_{2} /$ mol glicose (TDH de 8 e $2 \mathrm{~h}$ ). Os resultados indicam que pode ter ocorrido a formação de $\mathrm{H}_{2}$ a partir da rota fermentativa do etanol pelo menos no TDH de $8 \mathrm{~h}$. Porém o maior HY (1,91 mol $\mathrm{H}_{2} / \mathrm{mol}$ glicose) ocorreu quando a produção de etanol foi apenas 1,87\% (TDH de 2 h) dos metabólitos gerados, indicando a baixa influência da produção desse metabólito na formação de $\mathrm{H}_{2}$.
\end{abstract}

\section{INTRODUÇÃO}

O processo fermentativo de digestão anaeróbia é considerado uma alternativa atraente para produção de energia de forma sustentável pela possibilidade de utilização de vários tipos de resíduos industriais e domésticos ricos em carboidratos como substrato para produção de energia, além de minimizar os danos causados pelo descarte desse material de forma inadequada no meio ambiente (REIS, 2010).

A produção de etanol tem chamado atenção pela sua utilização como aditivo a gasolina em substituição ao MTBE (éter metil-terciário butílico) e também pode ser utilizado como substrato para produção de biodiesel (U.S. DEPARTMENT OF ENERGY, 1997; GRETHLEIN e JAIN, 1992; TAKESHI et al., 2005). Desta forma, a conversão de matérias-primas de biomassa para produção de bioetanol e biodiesel é a tecnologia de bioenergia fortemente focada neste momento (DEMIRBAS, 2007). No entanto, o hidrogênio como uma fonte de energia limpa, sustentável e eficiente, é considerado de fundamental importância no fornecimento de energia no futuro (DAS e VEZIROGLU, 2001).

O processo fermentativo de obtenção de hidrogênio tem como vantagens a possibilidade de produção contínua, já que não necessita da presença de luz solar; a alta velocidade de reação e pela 
facilidade da reprodução das bactérias fermentativas para suprir o meio de produção (NICODEMOS et al., 2008), além da utilização de águas residuárias para produção de hidrogênio (MIZUNO et al., 2000). Além da produção de hidrogênio, o processo fermentativo anaeróbio também produz ácidos orgânicos e álcoois (tais como o etanol) (LIN et al., 2006).

Dentre os principais metabólitos produzidos na acidogênese, os ácidos acético (Eq. 1) e butírico (Eq. 2) são considerados indicadores da produção de hidrogênio. Já na rota fermentativa do ácido propiônico (Eq. 3) há consumo de hidrogênio e, por esse motivo, deve ser evitada. A produção de etanol pode ocorrer através de duas rotas fermentativas. Em uma delas não há nem consumo nem produção de hidrogênio (Eq. 4), porém há consumo do substrato que poderia ser utilizado na produção de hidrogênio promovendo uma competição pelo substrato. Porém, existe uma rota fermentativa que produz ao mesmo tempo etanol e hidrogênio (Eq. 5).

$$
\begin{aligned}
& \mathrm{C}_{6} \mathrm{H}_{12} \mathrm{O}_{6}+2 \mathrm{H}_{2} \mathrm{O} \rightarrow 2 \mathrm{CH}_{3} \mathrm{COOH}+2 \mathrm{CO}_{2}+4 \mathrm{H}_{2} \quad \Delta G=-215,69 \mathrm{~kJ} / \mathrm{mol} \\
& \mathrm{C}_{6} \mathrm{H}_{12} \mathrm{O}_{6}+2 \mathrm{H}_{2} \mathrm{O} \rightarrow \mathrm{CH}_{3} \mathrm{CH}_{2} \mathrm{CH}_{2} \mathrm{COOH}+2 \mathrm{CO}_{2}+2 \mathrm{H}_{2} \quad \Delta G=-257,1 \mathrm{~kJ} / \mathrm{mol} \\
& \mathrm{C}_{6} \mathrm{H}_{12} \mathrm{O}_{6}+2 \mathrm{H}_{2} \rightarrow 2 \mathrm{CH}_{3} \mathrm{CH}_{2} \mathrm{COOH}+2 \mathrm{H}_{2} \mathrm{O} \quad \Delta \mathrm{G}=-358 \mathrm{~kJ} / \mathrm{mol} \\
& \mathrm{C}_{6} \mathrm{H}_{12} \mathrm{O}_{6} \rightarrow 2 \mathrm{CH}_{3} \mathrm{CH}_{2} \mathrm{OH}+2 \mathrm{CO}_{2} \quad \Delta \mathrm{G}=-235 \mathrm{~kJ} / \mathrm{mol} \\
& \mathrm{C}_{6} \mathrm{H}_{12} \mathrm{O}_{6}+\mathrm{H}_{2} \mathrm{O} \rightarrow \mathrm{C}_{2} \mathrm{H}_{5} \mathrm{OH}+\mathrm{CH}_{3} \mathrm{COOH}+2 \mathrm{H}_{2}+2 \mathrm{CO}_{2} \quad \Delta G=-201 \mathrm{~kJ} / \mathrm{mol}
\end{aligned}
$$

Apesar da rota do ácido propiônico ser a mais favorável de acordo com a energia livre de Gibbs, o controle das condições de operação do reator pode fazer com que esta rota seja evitada e que ocorra a produção de hidrogênio e etanol.

Embora a produção de hidrogênio pela rota fermentativa do etanol (produção máxima de 2 mol $\mathrm{H}_{2} / \mathrm{mol}$ glicose) seja menor do que na rota do ácido acético (produção máxima de $4 \mathrm{~mol} \mathrm{H}_{2} / \mathrm{mol}$ glicose), é possível ocorrer a produção dos dois biocombustíveis por meio de uma operação adequada do processo fermentativo visando otimizar o ganho energético.

O objetivo deste trabalho foi avaliar a produção de hidrogênio e etanol em reator anaeróbio de leito fluidizado a partir de água residuária do processamento da mandioca - a manipueira. 


\section{MATERIAIS E MÉTODOS}

\section{1.Água Residuária - Manipueira}

Nesse estudo foi adotada a manipueira como substrato por ser um efluente agroindustrial bastante gerado em pequenas indústrias de processamento de mandioca de diversos municípios de Alagoas. A coleta das amostras utilizadas nesse projeto foi obtida numa indústria de farinha de mandioca localizada no município de Taquarana no Estado de Alagoas.

A água residuária utilizada foi composta por uma solução com manipueira a uma concentração de $4000 \mathrm{mg} / \mathrm{L}$ e alguns suplementos, como ureia $(125 \mathrm{mg} / \mathrm{L})$, cloreto de cálcio $(47 \mathrm{mg} / \mathrm{L})$, fosfato de potássio monobásico $(85 \mathrm{mg} / \mathrm{L})$, fosfato de sódio dibásico $(33,4 \mathrm{mg} / \mathrm{L})$, conforme Amorim et al. (2009).

\subsection{Reator Anaeróbio de Leito Fluidizado - RALF}

O reator anaeróbio de leito fluidizado utilizado foi construído em acrílico transparente com uma espessura de $5 \mathrm{~mm}$, possuindo uma altura de 190 centímetros e 5,3 cm de diâmetro interno, com o volume total de $4192 \mathrm{~cm}^{3}$.

O reator foi preenchido por partículas de argila expandida (cinasita) até uma altura de aproximadamente $90 \mathrm{~cm}$ da base do reator. A argila expandida utilizada foi selecionada na faixa granulométrica 2,80-3,35mm e com densidade maior que a da água.

Duas bombas foram acopladas ao reator a fim de garantir sua alimentação e a recirculação do substrato. O reator foi operado à temperatura ambiente. A variação da temperatura foi acompanhada por um termômetro. A variação da temperatura ao longo do experimento foi de $23-31^{\circ} \mathrm{C}$.

O esquema de instalação e operação do reator anaeróbio de leito fluidizado pode ser observado na Figura 1. 


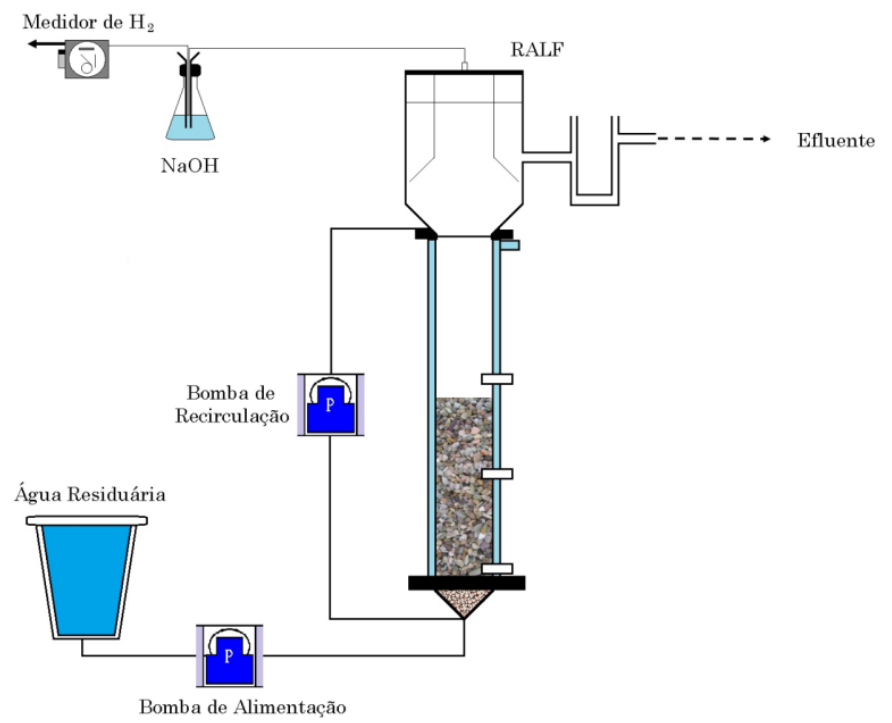

Figura 1 - Esquema de instalação do reator anaeróbio de leito fluidizado.

\subsection{Operação do Reator}

A operação do RALF foi conduzida continuamente ao longo de 164 dias. A DQO afluente a ser utilizada ao longo do experimento foi estabelecida em torno de $4000 \mathrm{mg} / \mathrm{L}$, de acordo com Amorim (2009). No total, foram cinco fases experimentais. As características de cada fase podem ser observadas na Tabela 1.

A argila expandida (cinasita) garantiu o maior contato entre o substrato e a biomassa. A sua massa foi de aproximadamente $1,065 \mathrm{~kg}$.

Optou-se por não controlar o pH durante a operação do reator para observar o comportamento do sistema, obtendo a média do $\mathrm{pH}$ efluente do reator entre 4,18-5,58.

Tabela 1 - Vazão, Tempo de Detenção Hidráulica (TDH) e Taxa de Carregamento Orgânico (TCO) adotados em cada fase experimental.

\begin{tabular}{|c|c|c|c|c|}
\hline $\begin{array}{c}\text { Fase } \\
\text { Experimental }\end{array}$ & $\begin{array}{c}\text { Tempo de Operação } \\
\text { (dias) }\end{array}$ & $\begin{array}{c}\text { TDH } \\
\text { (hora) }\end{array}$ & $\begin{array}{c}\text { Vazão } \\
(\mathbf{m L / h})\end{array}$ & $\begin{array}{c}\text { TCO } \\
\left(\mathbf{k g} / \mathbf{m}^{\mathbf{3}} \mathbf{d}\right)\end{array}$ \\
\hline 1 & 35 & 8 & 524,0 & 12,0 \\
\hline 2 & 47 & 6 & 698,7 & 16,0 \\
\hline 3 & 45 & 4 & 1048,0 & 24,0 \\
\hline 4 & 27 & 2 & 2096,0 & 48,0 \\
\hline 5 & 10 & 1 & 4192,0 & 96,0 \\
\hline
\end{tabular}




\section{RESULTADOS}

A Figura 2 apresenta o rendimento da produção de hidrogênio e de etanol em função do tempo de detenção hidráulica (TDH).

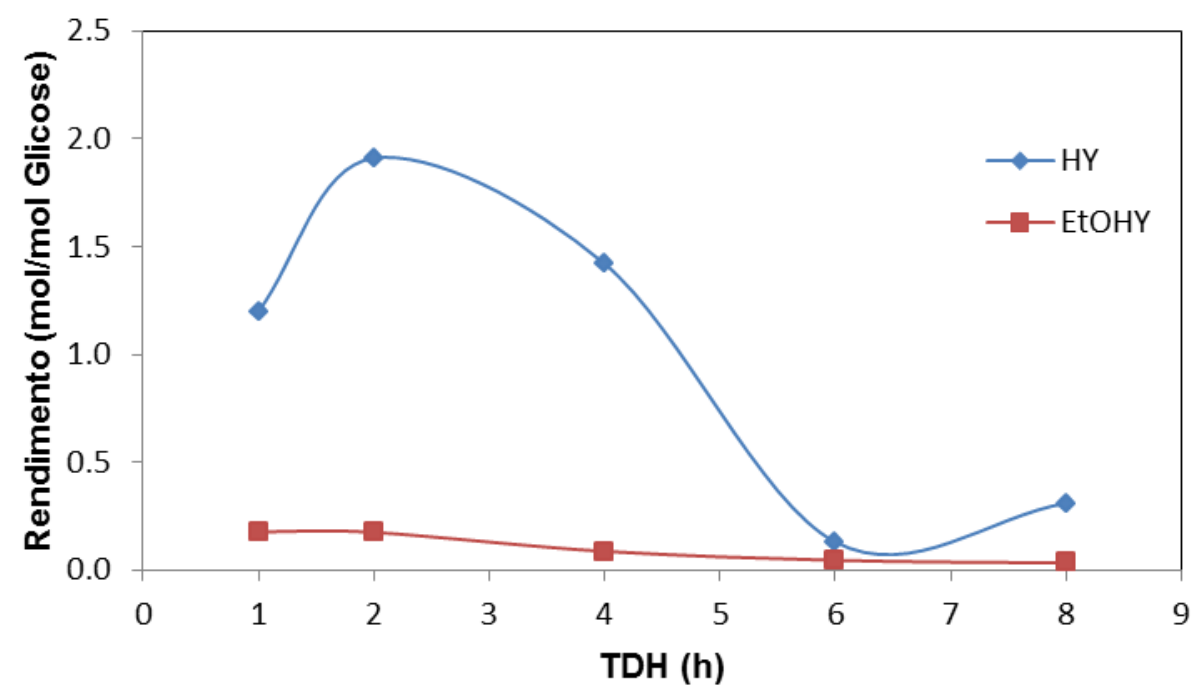

Figura 2 - Rendimento da produção de hidrogênio e etanol em função do tempo de detenção hidráulica.

Em relação a produção de hidrogênio, pode-se observar que o rendimento aumentou em função da redução do TDH de 8 para 2 h. Porém no TDH de 1 h houve uma redução desse rendimento. Trabalhos anteriores utilizando RALF observaram esse mesmo comportamento (SHIDA, 2008; AMORIM, 2009; BARROS, 2009; REIS, 2010). Amorim (2009) justifica tal comportamento devido provavelmente à sobrecarga aplicada ao reator por conta da elevada taxa de carregamento orgânica (TCO) ou por limitações cinéticas.

Barros (2009) observou a redução do rendimento da produção de hidrogênio quando aplicadas TCO acima de $150 \mathrm{~kg} / \mathrm{m}^{3} \mathrm{~d}$.

Nesta pesquisa, a TCO variou de $28-126 \mathrm{~kg} / \mathrm{m}^{3} \mathrm{~d}$ quando o TDH passou de 8 para $2 \mathrm{~h}$. no TDH de $1 \mathrm{~h}$, a TCO atingiu $161 \mathrm{~kg} / \mathrm{m}^{3} \mathrm{~d}$, valor acima do especificado como limite por Barros (2009). Esse aumento da TCO pode ter provocado a redução do rendimento de hidrogênio nesta fase.

Em relação ao rendimento da produção de etanol, observa-se um pequeno aumento em função da redução do TDH. Porém, o rendimento foi discreto durante toda a operação do reator variando de 0,03-0,18 mol EtOH/mol glicose quando o TDH passou de 8 para $1 \mathrm{~h}$.

A Figura 3 apresenta os metabólitos observados em cada fase experimental. 


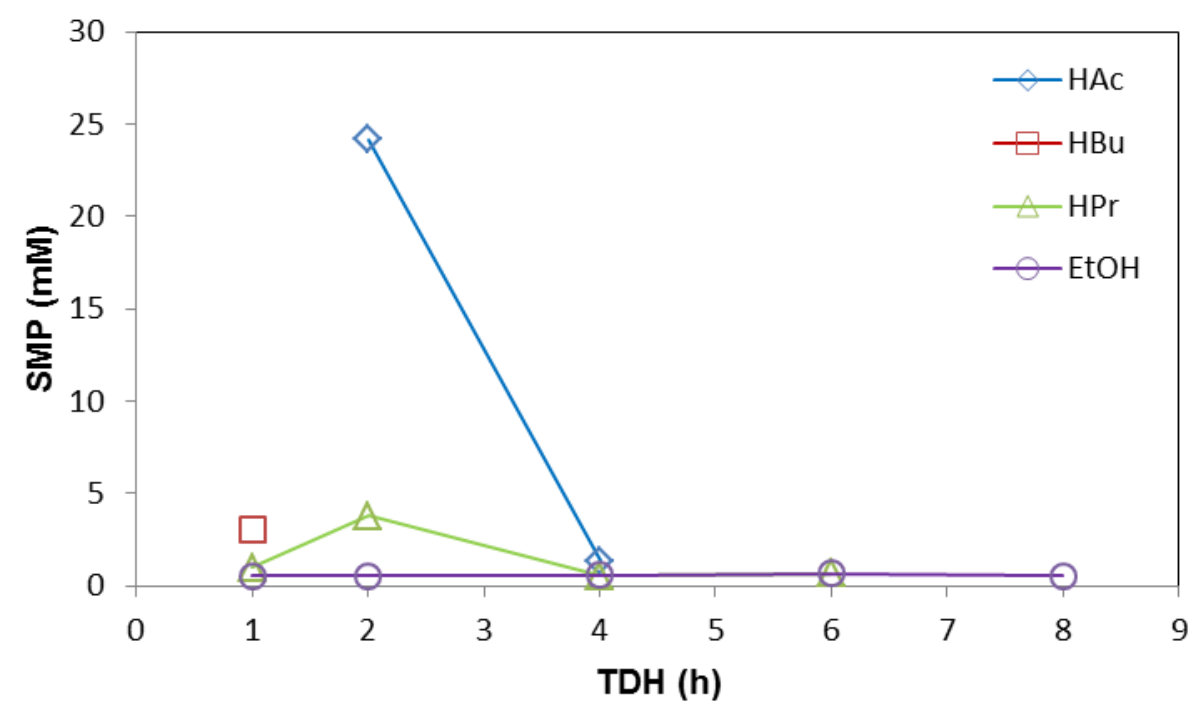

Figura 3 - Metabólitos produzidos durante a operação do RALF em função do TDH.

De acordo com a Figura 3, observa-se que o metabólito mais produzido na fase cujo TDH aplicado foi $2 \mathrm{~h}$ foi o ácido acético. Como a rota fermentativa deste metabólito é a que mais favorece a produção de hidrogênio (Eq. 1), justifica o maior rendimento da produção de hidrogênio nesta fase.

A produção de etanol foi praticamente constante durante todas as fases experimentais $(0,56 \pm$ 0,06 mM). Porém, observa-se que na fase de TDH de $8 \mathrm{~h}$, o etanol foi o único metabólito produzido. Isso indica a possível produção de hidrogênio a partir da rota fermentativa que produz ao mesmo tempo etanol e hidrogênio (Eq. 5).

Wu et al. (2007) utilizaram reator anaeróbio de leito fluidizado e reator de leito empacotado para investigar a produção simultânea de biohidrogênio e bioetanol a partir de substratos sintéticos a base de frutose, sacarose e glicose. No RALF, quando os autores utilizaram substrato a base de frutose, o rendimento máximo de hidrogênio e etanol foram de $0,56 \mathrm{~mol} \mathrm{H}_{2} / \mathrm{mol}$ hexose e $0,65 \mathrm{~mol}$ $\mathrm{EtOH} / \mathrm{mol}$ hexose, respectivamente. Já quando o substrato foi a base de sacarose os rendimentos máximos foram 0,64 mol $\mathrm{H}_{2} / \mathrm{mol}$ hexose e $0,49 \mathrm{~mol} \mathrm{EtOH} / \mathrm{mol}$ hexose. Enquanto que quando o substrato foi base de glicose, os rendimentos máximos foram $1,04 \mathrm{~mol} \mathrm{H}_{2} / \mathrm{mol}$ hexose e $0,33 \mathrm{~mol}$ $\mathrm{EtOH} / \mathrm{mol}$ hexose.

Os resultados encontrados pelos autores apontam condições que promoveram maior equilíbrio entre as produções de hidrogênio e etanol.

\section{CONCLUSÕES}

Este trabalho investigou a produção de hidrogênio e etanol em reator anaeróbio de leito fluidizado alimentado com manipueira. Os resultados indicam a possibilidade de produção de hidrogênio e etanol simultaneamente (Eq. 5). Houve formação do etanol em todas as fases 
experimentais. Na fase cujo TDH foi de $8 \mathrm{~h}$, houve apenas a formação de hidrogênio e etanol, indicando a formação de hidrogênio exclusivamente a partir da rota metabólica do etanol. Nas demais fases outros metabólitos foram observados (ácido acético, ácido butírico e ácido propiônico). Na fase de TDH de $2 \mathrm{~h}$ foi observado o maior rendimento da produção de hidrogênio. Já o rendimento da produção de etanol foi favorecido com a redução do TDH.

\section{REFERÊNCIAS BIBLIOGRÁFICAS}

AMORIM, E. L. C. Efeito da concentração de glicose e da alcalinidade na produção de hidrogênio em reator anaeróbio de leito fluidificado. São Carlos. 2009. Tese de Doutorado. Escola de Engenharia de São Carlos-Universidade de São Paulo, 2009.

BARROS, A. R. Influência de diferentes materiais suporte na produção de hidrogênio em reator anaeróbio de leito fluidificado. São Carlos. 2009. Dissertação de Mestrado. Escola de Engenharia de São Carlos-Universidade de São Paulo, 2009.

DAS, D.; VEZIROGLU, T.N. Hydrogen production by biological processes: a survey of literature. Int J Hydrogen Energy. v. 26, p.13-28, 2006.

DEMIRBAS, A. Progress and recent trends in biofuels. Prog Energy Combus Sci. v. 33, p. 1-18, 2007.

GRETHLEIN, A.J.; JAIN, M.K. Bioprocessing of coal-derived synthesis gas by anaerobic bacteria. Focus Tibtech. v. 10, p. 418-23, 1992.

LIN, C.Y.; HUNG, C.H.; CHEN, C.H.; CHUNG, W.T.; CHENG, L.H. Effect of initial cultivation pH on fermentative hydrogen production from xylose using natural mixed cultures. Process Biochem. v. 41, p. 1383-90, 2006.

MIZUNO, O. et al. Characteristics of hydrogen production from bean curd manufacturing waste by anaerobic microflora. Water Science Technology, v. 42, p. 338-345, 2000.

NICODEMOS, R. M.; LIMA, A. M.; ASSIS, A. M. Produção de hidrogênio a partir da fermentação de compostos orgânicos. In: ENCONTRO INTERNO, 7; SEMINÁRIO DE INICIAÇÃO CIENTÍFICA, 12., 2008. Uberlândia. Anais... Uberlândia:UFU, 2008.

REIS, C. M. Efeito da velocidade ascensional na produção de hidrogênio em reator anaeróbio de leito fluidificado. São Carlos. 2010. Dissertação de Mestrado. Escola de Engenharia de São Carlos-Universidade de São Paulo, 2010.

SHIDA, G. M. Produção de hidrogênio e ácidos orgânicos por fermentação acidogênica em reator anaeróbio de leito fluidificado. São Carlos. 2008. Dissertação de Mestrado. Escola de engenharia de São Carlos-Universidade de São Paulo, 2008.

TAKESHI, I.; NAKASHIMADA, Y.; SENBA, K.; MATSUI, T.; NISHIO, N. Hydrogen and ethanol production from glycerol-containing wastes discharged after biodiesel manufacturing process. $J$ 
Biosci Bioeng. v. 100, p. 260-5, 2005.

U.S. DEPARTMENT OF ENERGY. Alternative to traditional fuels: 1997-advanced data. Washington, DC: US Department of Energy; 1997.

WU, K.J.; CHANG, C.F.; CHANG, J.S.. Simultaneous production of biohydrogen and bioethanol with fluidized-bed and packet-bed bioreactors containing immobilized anaerobic sludge. Process Biochemistry, v. 42, p. 1165-1171, 2007. 